\title{
MEK inhibitor augments antitumor activity of B7-H3- redirected bispecific antibody
}

\section{Hongjian Li \\ Sichuan University \\ Cheng Huang \\ Sichuan University \\ Zongliang Zhang \\ Sichuan University \\ Yunyu Feng \\ Sichuan University \\ Zeng Wang \\ Sichuan University \\ Xin Tang \\ Sichuan University \\ Kunhong Zhong \\ Sichuan University}

Yating $\mathrm{Hu}$

Sichuan University

Gang Guo

Sichuan University

Liangxue Zhou

Sichuan University

Wenhao Guo

Sichuan University

Jianguo Xu

Sichuan University

Hui Yang

Sichuan University

Aiping Tong ( $\square$ aipingtong@scu.edu.cn )

https://orcid.org/0000-0002-3392-5443

\section{Research}


Keywords: trametinib, B7-H3, immunotherapy, bispecific antibody, non-small cell lung cancer, bladder cancer

Posted Date: April 17th, 2020

DOI: https://doi.org/10.21203/rs.3.rs-22616/v1

License: (c) (1) This work is licensed under a Creative Commons Attribution 4.0 International License. Read Full License 


\section{Abstract \\ Background}

Targeting cancer antigens by $\mathrm{T}$ cell-engaging bispecific antibody (BiAb) or chimeric antigen receptor $\mathrm{T}$ cell therapy has achieved successes in haematological cancers, but attempts to use them to fight solid cancers have been disappointing, in part due to antigen escape. MEK inhibitor had limited activity as a single agent, but enhanced antitumor activity when combined with other therapies, such as targeted drugs or immunotherapy agents. This study aimed to analyze the expression of B7-H3 in non-small-cell lung cancer (NSCLC) and bladder cancer (BC) and to evaluate the combinatorial antitumor effect of a B7$\mathrm{H} 3 \times \mathrm{CD} 3 \mathrm{BiAb}$ with MEK inhibitor trametinib.

\section{Methods}

We analyzed the mRNA expression of B7-H3 in NCSLC and BC using Oncomine database and validated its expression by immunohistochemistry staining of clinical samples. B7-H3 expression and the effects of trametinib on RAS-mutated NSCLC and BC cell lines were determined by flow cytometry. Antitumor efficacy of $\mathrm{B} 7-\mathrm{H} 3 \times \mathrm{CD} 3 \mathrm{BiAb}$ alone and its combination with trametinib were evaluated both in vitro and in vivo.

\section{Results}

B7-H3 was highly expressed in NSCLC and BC compared with normal samples and its increased expression was associated with poor prognosis. Treatment with trametinib alone could induce apoptosis in tumor cell, while has no effect on T cell proliferation, and a noticeable elevation of B7-H3 expression in tumor cells was also observed following treatment. B7-H3 × CD3 BiAb specifically and efficiently redirected their cytotoxicity against B7-H3-overexpressing tumor cells both in vitro and in xenograft mouse models, which was synergized by trametinib. While trametinib treatment alone affected tumor growth, the combined therapy increased T cell infiltration and significantly suppressed tumor growth.

\section{Conclusion}

Together, these data suggest that combination therapy with $\mathrm{B} 7-\mathrm{H} 3 \times \mathrm{CD} 3 \mathrm{BiAb}$ and MEK inhibitor may serve as a new therapeutic strategy in the future clinical practice for the treatment of NSCLC and BC.

\section{Background}

Lung cancer is the second most common cancer with a 5-year survival rate of $19 \%$ [1]. Non-small-cell lung cancer (NSCLC) accounts for $85 \%$ of all lung cancer diagnoses [2, 3]. Bladder cancer (BC) is the 9th most common cancer worldwide, which is responsible for more than 160,000 deaths each year $[1,4]$. 
Although the progress in modern treatment modalities including surgical resection, chemotherapy, radiotherapy and targeted therapy, patients with NSCLC and BC still suffer from significant treatment failure due to high rates of recurrence and poor prognosis for advanced disease $[5,6]$. Thus, novel treatment regimens are urgently needed for NSCLC and BC.

B7-H3, a type I transmembrane protein, is a member of the B7 family with immune modulatory functions [7]. The expression of $\mathrm{B} 7-\mathrm{H} 3$ is absent or low in normal human tissues [8-10]. Interestingly, it is frequently upregulated in a high proportion of human malignancies, such as head and neck cancer and medulloblastoma $[8,10-12]$. As a result, $\mathrm{B} 7-\mathrm{H} 3$ is considered as a promising biomarker and target for cancer immunotherapy. A few B7-H3-directed CAR T cells have been undertaken in preclinic models [1317]. Besides, recent studies have suggested that $\mathrm{B} 7-\mathrm{H} 3$ promotes the migration and invasion of NSCLC and $B C$ cells $[12,18]$, and overexpression of $B 7-H 3$ is usually related to a worse clinical prognosis $[11,19]$. Therefore, B7-H3 may be an attractive target for NSCLC and BC.

It has become a major breakthrough for tumor immunotherapy by engaging the immune system to eradicate tumor cells. In the forefront of these treatments, the most promising approach is T-cell-based therapies, including the T-cell-engaging bispecific antibody (BiAb). It can facilitate $T$ cell recruitment and target cell killing by binding to the T-cell receptor CD3 subunit and tumor cells via a tumor-associated antigen (TAA) [20]. Compared with CAR-T cell therapy, the strength of T-cell-engaging BiAb lies in the fact that it recruits endogenous $T$ cells to tumors without the need to manipulate $T$ cells ex vivo in a patientspecific manner [21, 22]. So far, a few studies on T-cell-engaging BiAb have been reported for various cancer treatment [23-28]. However, novel strategies are still needed to overcome antigen escape in solid tumors, which is a main drawback of BiAb [29].

Abnormal mitogen-activated protein kinase (MAPK) signaling is associated with the occurrence and development of various cancers [30]. Aberrant activation of MAPK can be induced by a variety of mutations, such as RAS, RAF, and MEK1/2 [31]. Notably, MEK1/2 mutations are common in several cancers, including lung cancer and bladder cancer [30,32-34]. Trametinib is an oral, reversible and highly selective inhibitor of MEK1/2 [34]. Compared with other inhibitors, trametinib exhibits superior performance due to its favorable pharmacokinetics, long biological half-life, minor side effect and low risk of adverse drug reactions [31]. Inhibition of oncogenic MAPK signaling by trametinib has been an effective strategy to treat metastatic melanoma [35]. However, there are limitations for trametinib to fight against solid cancers, due to the acquisition of resistance after repeated administration [36]. Thus, combination with trametinib and immunotherapy may be a promising therapeutic schedule.

Herein, to develop a new NSCLC and BC treatment modality, we tried to construct a B7-H3 $\times$ CD3 BiAb that binds to $T$ cells and target surface expressed on tumor cells. In addition, we selected a MEK inhibitor trametinib for combination therapy. We hypothesized that the BiAb and trametinib could separately mitigate tumor cells' malignant phenotype. Furthermore, we sought to test whether trametinib would improve the bispecific antibody responses in vitro and in vivo. 


\section{Material And Method}

Mice

Six-to-eight-week-old immunodeficient NOD-SCID female mice were purchased from the Model Animal Resource Information Platform of Nanjing University. Mice were maintained under specific pathogen-free facilities at Sichuan University. All procedures met the requirements of the National Institutes of Health and Institutional Animal Care and Use Committee. The animal experiments were approved by the West China Hospital of Sichuan University Biomedical Ethics Committee (Ethical approval document: 2018061).

Tissue microarray and blood samples

Human tissue microarrays for immunohistochemistry (IHC) were purchased from Xi'an Alenabio and Shanghai Outdo Biotech of China. Blood samples were taken from healthy donors and were used for isolation of human peripheral blood mononuclear cells (PBMCs).

Cell lines and culture conditions

Human NSCLC cells A549 (which have the KRAS ${ }^{\mathrm{Q} 61 \mathrm{H}}$ mutation), H460 (which have the KRAS ${ }^{\mathrm{G} 12 S}$ mutation), BC cells T24 (which have the HRAS ${ }^{\mathrm{G} 12 \mathrm{~V}}$ mutation) and HEK293T cell lines were purchased from ATCC. A549, H460 and HEK293T cell lines were maintained in Dulbecco's modified Eagle medium (Gibco) with 10\% fetal bovine serum (Gibco) and $2 \mathrm{mmol} / \mathrm{L}$ L-glutamine. T24 cell line was maintained in McCoy's 5A Medium (Gibco) with 10\% fetal bovine serum and 2 mmol/L L-glutamine.

PBMCs from healthy donors were isolated using density gradient centrifugation and activated by culturing with anti-CD3 mAb (OKT3, $100 \mathrm{ng} / \mathrm{mL}$, BioLegend), anti-CD28 mAb (CD28.2, 100 ng/mL, Sino Biological) and recombinant human interleukin-2 (IL-2) (100 units/mL, Life Science) in X-Vivo medium (Lonza) supplemented with $10 \%$ fetal bovine serum (heat inactivation at $56^{\circ} \mathrm{C}$ for 30 minutes) and $2 \mathrm{mM}$ L-glutamine and for 3 days.

Construction and production of B7-H3 × CD3 BiAb

The anti-B7-H3 single-chain variable fragment (scFv) sequence was derived from a highly specific monoclonal antibody against B7-H3 (clone mAb-J42) generated by our group using a standard hybridoma technique. cDNAs encoding the anti-B7-H3 scFv and anti-CD3 scFv (according to published amino acid sequences) were synthesized by commercial gene synthesis service (Genewiz). The two scFvs were linked by a G4S linker to construct a recombinant single-chain BiAb. The cDNAs were subcloned into an expression vector with a His tag at the C-terminal for protein purification.

HEK293T cells were transfected with the vector described above and cultured in the FreeStyle serum-free medium (Thermo Fisher Scientific) at $37^{\circ} \mathrm{C}, 5 \% \mathrm{CO}_{2}$. After 7 days, culture supernatant was harvested and pre-cleaned by $0.45-\mu \mathrm{m}$ filters. The BiAb was purified on Ni-NTA affinity columns and subsequently 
subjected to size exclusion chromatography. To assess the molecular mass of the BiAb, obtained samples were subjected to SDS-PAGE and stained with Coomassie brilliant blue.

Immunofluorescence staining

Cells were incubated in 24-well plates under standard cell culture conditions $\left(5 \times 10^{3}\right.$ cells per well). After 12 hours, cells were blocked with 5\% BSA for 15 minutes, stained with B7-H3 antibody (Abcam, ab227679) for 1 hours, Cy3-conjugated secondary antibody (Beyotime, A0516) for 40 minutes and DAPI (Beyotime) in the dark. Images were captured on a fluorescence microscopy.

Tumor tissues from the T cell group mice were collected and immediately froze at $-80^{\circ} \mathrm{C}$. Sections were fixed in pre-chilled acetone-methanol $(1: 1)$ for 20 minutes at $-20^{\circ} \mathrm{C}$ and then allowed to air-dry for 10 minutes before being blocked with 5\% BSA for 30 minutes. Subsequently, Sections were stained with B7H3 antibody (Abcam, ab227679) for 1 hour, FITC-conjugated secondary antibody (Beyotime, A0562) for 40 minutes and DAPI (Beyotime) in the dark. Images were captured on a fluorescence microscopy.

Flow cytometry

B7-H3 expression level on tumor cells was analyzed by flow cytometry. Cells were collected by centrifugation and incubated with the human B7-H3 antibody (BioLegend, 331605) for 20 minutes in the dark. After washing three times with PBS, the cells were resuspended in $500 \mu \mathrm{L}$ and analyzed using a NovoCyte ${ }^{\mathrm{TM}}$ Flow Cytometer (ACEA Bioscience) according to the manufacturer's protocols. For T cell phenotype analyses, human CD4 (BioLegend, 357419), CD8 (BioLegend, 344729), CD25 (BioLegend, 302629) and CD69 (BioLegend, 310909) antibodies were used and experiments were performed on a Fortessa flow cytometer (BD).

For apoptosis detection, Annexin $\mathrm{V}$ staining was measured by FITC-annexin-V Apoptosis Detection Kit I (4A Biotech). A549 and H460 cells $\left(5 \times 10^{5}\right)$ were treated for 48 hours with $10 \mu \mathrm{M}$ trametinib (MCE). Cells were collected and resuspended in $1 \times$ Binding Buffer, $100 \mu \mathrm{L}$ solution $\left(1 \times 10^{5}\right.$ cells $)$ was used to stain cells with $5 \mu \mathrm{L}$ FITC annexin $V$ for 15 minutes in the dark followed by the addition of $0.4 \mathrm{~mL}$ of $1 \times$ Binding Buffer and $10 \mu \mathrm{L}$ 7-AAD. Flow cytometry analysis was performed on a NovoCyte ${ }^{\mathrm{TM}}$ Flow Cytometer (ACEA Bioscience) according to the manufacturer's protocols.

For T cell proliferation assay, T cells were initially stained with carboxy fluorescein succinimidyl ester (CFSE) (Beyotime) and cultured in the presence or absence of $1 \mu \mathrm{M}$ trametinib. After 48 hours, cell proliferation was carried out by flow cytometry.

Western blotting

Total proteins were extracted from cells after treatment with the indicated concentrations of trametinib for 48 hours and quantified by BCA protein assay kit (Beyotime). Then, equal amount of proteins (10 $\mu \mathrm{g})$ was subjected to SDS-PAGE and transferred to polyvinylidene difluoride membranes. After that, the membranes were blocked with $5 \%$ milk for 1 hour. Subsequently, the membranes were stained with B7-H3 
(CST, 14058S), P-MEK1/2 (CST, 3958S), P-ERK1/2 (CST 4370S) and $\beta$-actin (ZSGB-BIO, TA09) antibodies for 1 hour, HRP-conjugated secondary antibody (Beyotime, A0208) for 1 hour. Images were captured by a ChemiScope 6000 Touch (Clinx).

Cell viability assay

Cells were seeded in 96-well plates and incubated overnight prior to treatment. After 48 hours with the indicated concentrations of trametinib, $10 \mu \mathrm{L}$ of the Cell Counting Kit-8 solution (Beyotime) was added to each well and incubated for 2 hours in the dark. Absorbance at $450 \mathrm{~nm}$ was measured in a microplate reader.

\section{Cytotoxicity Assays}

A 2D and 3D coculture models of tumor cells with human T cells were used to assess the cytotoxicity. In the 2D coculture model, A549, H460 or T24 cells were co-cultured with T cells at an E:T ratio of 1:4, 1:1 and 4:1, together with $1 \mu \mathrm{M}$ trametinib alone or in combination with $5 \mu \mathrm{g} / \mathrm{mL}$ BiAb. Images were captured at 12 and 24 hours. To assess the effect of cytotoxicity, Chromium-51 assay was carried out as described [14]. Tumor cells were labeled with sodium chromate (molecular formula, Na251CrO4) and incubated with T cells at an E:T ratio of 1:4, 1:1 and 4:1 for $4 \mathrm{~h}$. Then the radioactivity of the supernatants was measured by a gamma counter. The percentage of specific lysis was calculated by the formula: (test release-spontaneous release)/(maximal release-spontaneous release) $\times 100$.

For the 3D spheroid model, the method was performed according to our previous description [37]. In brief, $1 \times 10^{5}$ cells were added to the Matrigel-coated wells and cultured in serum-free DMEM (Gibco) with $2 \%$ B27 supplement (Gibco), $20 \mathrm{ng} / \mathrm{ml}$ human EGF (Sino Biological) and $20 \mathrm{ng} / \mathrm{ml}$ human bFGF (Sino Biological). After 5 days, human T cells were stained with CFSE (Beyotime) and added to the wells at the $\mathrm{E}: T$ ratio of $1: 1$, together with $5 \mu \mathrm{g} / \mathrm{mL}$ BiAb alone or in combination with $1 \mu \mathrm{M}$ trametinib for 12 hours. Cells were stained with DAPI (Beyotime) in the dark and images were captured on a fluorescence microscopy.

Analysis of Cytokine Secretion

Tumor cells were coculture with T cells alone or together with $5 \mu \mathrm{g} / \mathrm{ml} \mathrm{BiAb}$ in 24-well plates at different $\mathrm{E}: \mathrm{T}$ ratio with. After $24 \mathrm{~h}$, the supernatant was collected to evaluate the IFN- $\gamma$ secretion by ELISA kits (BioLegend) according to the manufacturer's protocols.

In vivo experiments

In the H460 and T24 xenograft experiments, $2 \times 10^{6} \mathrm{H} 460$ or T24 cells were subcutaneously injected into NOD-SCID mice and were randomly divided into four groups consisted of $n=5$ per group. From the tenth day on, trametinib $(0.6 \mathrm{mg} / \mathrm{kg})$ or vehicle control was administered for 10 consecutive days via oral gavage. On day 13 , all mice were intravenously treated with $8 \times 10^{6} \mathrm{~T}$ cells and from the day on, mice were intravenously treated with $100 \mathrm{U}$ IL-2 or in combination with $2 \mathrm{mg} / \mathrm{kg}$ BiAb or PBS for seven 
consecutive days. The mice in the combination treatment group received both trametinib and the BiAb at the above doses and schedule. The vehicle control of trametinib was a mixture of $30 \%$ PEG $400,0.5 \%$ Tween 80 and $5 \%$ propylene glycol. Bodyweight and tumor sizes were measured every three days. The tumor volume was calculated using the following equation: (length $\times$ width $\times$ width) $/ 2$.

$\mathrm{IHC}$ assay

Tumor, Heart, liver, spleen, lung and kidney sections from mice were preprocessed by paraformaldehyde and embedded in paraffin. After slicing into sections, slides were performed with H\&E staining. Tumor paraffin sections were immunostained with CD3 antibody (Servicebio, GB13014). All procedures followed the manufacturer's protocol. In brief, tissue sections were incubated at $65^{\circ} \mathrm{C}$ for $1 \mathrm{~h}$ to retrieve antigenicity, blocked with PBS containing $10 \%$ normal goat serum for $30 \mathrm{~min}$ at room temperature, and then incubated with primary antibody at $4{ }^{\circ} \mathrm{C}$ overnight. The sections were then incubated with secondary antibodies, and the staining was detected with 3,3'diaminobenzidine (ZSGB-Bio).

\section{Statistical analysis}

All in vitro results were representative of three separate experiments. Data were presented as the mean \pm standard deviation in figure legends. Statistical analyses were performed using GraphPad Prism 7.0. The difference between various experimental and control groups was examined by Student's t-test and considered significant at ${ }^{*}, \mathrm{P}<0.05 ; * \star, \mathrm{P}<0.01 ; * \star \star, \mathrm{P}<0.001$. For bioinformatic analysis of $\mathrm{B} 7-\mathrm{H} 3$, the relationship between $\mathrm{B} 7-\mathrm{H} 3$ expression and prognosis was performed using the dataset of the KaplanMeier Plotter (KM Plotter) [38]. The meta-analysis and mRNA expression of B7-H3 in tumor and normal tissues was analyzed by using the Oncomine [39]. The association of B7-H3 expression and the tumor stage were examined by data mining in Oncomine or The Cancer Genome Atlas (TCGA).

\section{Results}

\section{Analysis of B7-H3 expression and survival from Oncomine and TCGA database}

Based on the data, we analyzed the association of B7-H3 expression with survival in 1145 NSCLC and $404 \mathrm{BC}$ patients (Fig. 1a and 1b). As shown, higher expression of B7-H3 was significantly correlated to lower survival in both NSCLC $(P<0.001)$ and BC $(P<0.001)$. Then, we tested the presence of $B 7-H 3$ in major subtypes of NSCLC and BC. We found differential B7-H3 expression with significantly higher levels in NSCLC and BC subtypes as compared with normal lung and bladder samples ( $P<0.05$; Fig. $1 \mathrm{C}$ and $d)$. In addition, the results in the meta-analysis of the previous studies [40-45] further implied B7-H3 was highly expressed in NSCLC and BC samples compared to normal tissues (Fig. S1a and S1b). Finally, the association between B7-H3 expression and clinical stage of NSCLC or BC patients was also evaluated. There was no significant difference in the expression of $B 7-H 3(P=0.748$; Fig. 1 e $)$ in NSCLC patients with 
different pathologic stages. However, advanced stage BC patients were likely to show higher B7-H3 expression compared with early stage patients $(P=0.002$; Fig. 1f).

\section{Analysis of B7-H3 expression in NSCLC and BC tissues and cell lines.}

We performed IHC staining to identify the expression of B7-H3 in tissue microarrays, including tumor, tumor-adjacent, and normal tissues at different stages (Fig. 2a-C). The intensity of B7-H3 expression was markedly increased in malignant tumor and tumor-adjacent tissues compared to normal tissues. Then, we evaluated the expression of B7-H3 in A549, H460, T24 cell lines and H460, T24 xenograft models isolated from mice using immunofluorescence and flow cytometry. As shown, B7-H3 stained positively in NSCLC and BC cell lines (Fig. 2d) and isolated tumors (Fig. S2a and S2b). Likewise, the results of flow cytometry showed high expression of B7-H3 in A549, H460 and T24 cell lines (Fig. 2e and 2f). Together, these results indicated that the $\mathrm{B} 7-\mathrm{H} 3$ marker might serve as a clinical target for the treatment of patients with NSCLC and BC.

\section{MEK inhibitor trametinib suppressed cell growth and increased the expression of B7-H3 in NSCLC and BC cell lines.}

To explore the effect of MEK inhibitor trametinib on NSCLC and BC cell lines, we used flow cytometry and CCK-8 assay to investigate cell apoptosis and proliferation, respectively. The results of flow cytometry revealed that incubating $\mathrm{A} 549$ and $\mathrm{H} 460$ with trametinib induced cell apoptosis compared with the control groups (Fig. 3a). Similarly, cells were treated with various concentrations of trametinib and the results showed that trametinib has a dose-dependent killing effect on A549, H460 and T24 cells, identified via CCK8 assay (Fig. 3b). Furthermore, to investigate whether trametinib affected B7-H3 expression in cell lines, A549, H460 and T24 cells were cultured with different concentrations of trametinib for 48 hours and the expression levels were determined by flow cytometry. Compared to control groups, we found that B7-H3 expression was significantly upregulated in A549, H460 and T24 cells after trametinib stimulation (Fig. 3c and 3d). The elevation of B7-H3 expression was confirmed by western blot (Fig. 3e). Treatment with trametinib also inhibit MEK signaling, based on lower levels of phosphorylated MEK/ERK (Fig. 3e). In addition, we did not find that trametinib suppressed the proliferation of human T cells by CFSE staining. (Fig. 3f)

\section{Generation and characterization of B7-H3 × CD3 BiAb}

B7-H3 $\times$ CD3 BiAb was engineered by combining a B7-H3 single chain variable region (scFv) with a CD3 scFv. Each scFv contained a corresponding light chain (VL) and heavy chain $(\mathrm{VH})$ joined together by a 5amino-acid (G4S) linker (Fig. 4a and 4b). Figure 4c shows the SDS-PAGE analysis of purified B7-H3 $\times$ CD3 $\mathrm{BiAb}$. Before the in vitro and in vivo antitumor assay, the ratio of $\mathrm{CD} 4^{+} / \mathrm{CD} 8^{+}$human $\mathrm{T}$ cells stimulated by B7-H3 $\times$ CD3 BiAb was analyzed by flow cytometry (Fig. 4d). Two days after stimulation, there was no significant difference between the BiAb stimulated T cells and control group. 
To evaluate the cytotoxicity of the BiAb towards cancer cell lines, coculture assay was carried out to photograph the growth of A549, H460 and T24 cells after 12-hour or 24-hour incubation periods. Clusters of $\mathrm{T}$ cells and the lysis of cancer cells were observed in groups with the BiAb (Fig. 4e-g and S3a-c). Next,

${ }^{51} \mathrm{Cr}$-release cytotoxic assays were carried out to test the specific antitumor effect of the BiAb and the results under different E/T ratios are shown in Fig. 4h. Specific lysis was observed in groups with the $\mathrm{BiAb}$ compared to control groups. Furthermore, supernatants in coculture assay were collected to determine the relative cytokine secretion level. A significant increase in IFN- $\gamma$ release can be detected in groups with the BiAb (Fig. 4i).

\section{Cytotoxicity of $\mathrm{B} 7-\mathrm{H} 3 \times \mathrm{CD} 3 \mathrm{BiAb}$ in combination with trametinib is superior to single agents in vitro}

We sought to investigate whether combining $\mathrm{B} 7-\mathrm{H} 3 \times \mathrm{CD} 3 \mathrm{BiAb}$ and trametinib can enhance tumor cell killing in NSCLC and BC cell lines. Coculture assay was performed and representative bright-field images were shown in Fig. 5a. T cells in coculture assay were collected and the expression levels of CD25 and CD69 were detected to access T-cell activation (Fig. $5 b$ and $5 c$ ). T cells, together with BiAb alone or in combination with trametinib, exhibited higher degrees of CD25 and CD69 activation compared to control and trametinib alone groups. The ratio of CD4 and CD8 positive T cells was shown in Fig. S4a and S4b. The proportion of $\mathrm{CD} 4^{+} / \mathrm{CD} 8^{+} \mathrm{T}$ cells was not significantly altered throughout the coculture assay. Furthermore, in the three-dimensional (3D) cancer spheroid model, although both groups with $\mathrm{T}$ cells and the BiAb were found to target tumorsphere, groups with trametinib were more lethal to spheres than groups without it (Fig. 5d and 5e).

\section{B7-H3 $\times$ CD3 BiAb in combination with trametinib synergistically inhibited tumor growth in xenograft models.}

To determine the in vivo efficacy of B7-H3 $\times$ CD3 BiAb and trametinib, NSCLC cell line $\mathrm{H} 460$ and BC cell line T24 were used in mice xenograft models. The schema is presented in Fig. 6a. After subcutaneously injected with $\mathrm{H} 460$ or T24 cells, mice were daily administered with trametinib starting on day 10 . Then mice were treated with identical doses of $T$ cells, $T$ cells with trametinib, $T$ cells with the BiAb or $T$ cells with the BiAb and trametinib at indicated time points. In the present study, NSCLC and BC tumor mass growth were significantly suppressed by trametinib, the BiAb or the BiAb combined with trametinib (Fig. $6 \mathrm{~b}$ and $6 \mathrm{c}$ ). On day 21, although trametinib or the BiAb was able to inhibit tumor growth, the combination group was significantly more effective (Fig. 6d and 6e). During the experiment, no abnormalities were observed in vital organs via HE staining (Fig. S5). Also, there was no significant bodyweight loss in all groups (Fig. $6 \mathrm{f}$ and $6 \mathrm{~g}$ ). To further examine the recruitment of T cells in micebearing tumors, cell surface marker CD3 was analyzed by IHC. CD3 ${ }^{+} \mathrm{T}$ cells were seen in all groups (Fig. $6 \mathrm{~h}$ and $6 \mathrm{i}$ ). Among these groups, the combined treatment group exhibited the highest number of $\mathrm{CD}^{+}$TILs significantly, followed by the group treated with the BiAb and T cells. The results of the study are summarized in a model diagram (Fig. 6j)

\section{Discussion}


According to our data, overexpression of $\mathrm{B} 7-\mathrm{H} 3$ was revealed and it was associated with poor survival in NSCLC and BC. Both B7-H3 $\times$ CD3 BiAb and trametinib were able to inhibit NSCLC and BC cell growth in vitro and in vivo. A combination of trametinib and B7-H3 $\times$ CD3 BiAb inhibited NSCLC and BC cell growth and killed them by activating $T$ cell in vitro as well as promoting $T$ cell infiltration in vivo. In past studies, the inhibitory effect of trametinib on KRAS or BRAF mutant cell line has been confirmed $[34,46]$. Our data in A549 and $\mathrm{H} 460$ cell lines again corroborates the above results. It should be noted that we discovered trametinib could suppress the growth of T24 cells with HRAS mutation. Similarly, MEK inhibitor might be partly responsible for HRAS-mutated tumor reduction according to a phase I trial [47]. This hint HRAS mutation cells may sensitize towards treatment with MEK inhibitors.

A previous report described the potential immunosuppressive activity of MEK inhibitors in vitro, which has limited the assessment of MEK inhibitor combination with immunotherapies [48]. However, our data of CFSE labeling experiments did not show that trametinib could inhibit the proliferation of $T$ cells. The difference in results is probably due to the fact that $T$ cells were activated before adding trametinib in our experiments compared to the previous study that activated T cells during trametinib treatment. A recent research has implied that trametinib selectively blocked activation of naive $T$ cells but did not suppress $T$ cells which were already activated in vitro [49]. Their results are in line with ours. Another study has demonstrated that MEK inhibitors potentiated rather than hindered antitumor T cells by impairing TCRdriven apoptosis [50]. Similarly, we showed trametinib enhanced T cell activation in the coculture assay. In addition, several studies have combined MEK inhibitor with PDL1 antibody or oncolytic virus and obtained ideal results [50-52]. Taken together, these results suggest that blockage of MAPK signaling is critical and effective to prime and synergize tumors in response to immunotherapy.

It is essential to understand the effects of targeted agents on antitumor immune response. MEK inhibitors have been found to up- or down-regulate the expression of immune molecules, including MHC class I, PDL1 in previous studies $[49,52-54]$. These contradictory results indicate that the differential expression of immune molecules may be context-dependent. Notably, a recent study has identified that there was a significant up-regulation of B7-H3 in the trametinib-treated A375 melanoma cell line [49]. The present study had similar findings. We noticed that MEK inhibitor trametinib increased B7-H3 expression in human NSCLC and BC cell lines. This may be attributed to the complex regulatory pathways of B7-H3 which remains largely unknown. According to previous studies, $\mathrm{B} 7-\mathrm{H} 3$ can promote cell invasion via the STAT3 signaling pathway $[55,56]$. Meanwhile, trametinib was reported to upregulate MHC class I and PDL1 by inducing STAT3 activation [52]. However, whether trametinib regulates B7-H3 via the STAT3 or other signaling pathways requires further investigation. From our data, we can only infer it is feasible for combination therapy with trametinib and agents targeting B7-H3. Additional research is definitely needed to clarify the mechanism underlying our findings.

The most important factor in immunotherapy is to select a proper TAA to target. B7-H3 has been identified as promising immunotherapeutic targets for anticancer therapy, as it is aberrantly upregulated on the cell surface of many types of tumors [8, 10-12]. Several B7-H3 monoclonal antibodies have been tested in patients with refractory neoplasms (MGA271, clone 84D) [57] and glioma (antibody-drug 
conjugate, clone 8H9) [58]. Recently, a B7-H3 × CD3 bispecific molecule (MGD009) is in clinical trials for solid tumors [8]. In our research, B7-H3 is confirmed abundant in NSCLC, BC cell lines and tissues, but it is expressed at low levels or almost undetectable in normal tissues. Moreover, according to our data, the therapeutic efficacy of $\mathrm{B} 7-\mathrm{H} 3 \times \mathrm{CD} 3 \mathrm{BiAb}$ was significant and there were no related acute side effects. These results give further evidence that $\mathrm{B} 7-\mathrm{H} 3$ can act as an effective therapeutic target for the clinical management of NSCLC and BC.

\section{Conclusion}

In summary, we revealed that trametinib could inhibit cell proliferation and upregulate the expression of B7-H3 in tumor cells. B7-H3 $\times$ CD3 BiAb was able to directly guide T cell to kill tumor cells in human NSCLC and BC models. Moreover, we found a synergistic effect between MAPK inhibitor trametinib and $\mathrm{B} 7-\mathrm{H} 3 \times \mathrm{CD} 3 \mathrm{BiAb}$. Although the molecular mechanism underlying the combination treatment needs to be further elucidated, these data provide new insights into NSCLC and BC treatment using a combination with MEK inhibitor and B7-H3-redirected immunotherapy.

\section{Abbreviations}

NSCLC: Non-small-cell lung cancer; BC: Bladder cancer; BiAb: Bispecific antibody; TAA: Tumor-associated antigen; MAPK: Mitogen-activated protein kinase; IHC: immunohistochemistry; PBMCs: Peripheral blood mononuclear cells; scFv: Single-chain variable fragment; CFSE: Carboxy fluorescein succinimidyl ester; KM Plotter: Kaplan-Meier Plotter; TGGA: The Cancer Genome Atlas;

\section{Declarations}

\section{Acknowledgements}

Not applicable.

\section{Authors' contributions}

AT, $\mathrm{HL}, \mathrm{CH}$ and $\mathrm{HY}$ designed the study. YF analyzed the data from Oncomine and TCGA. HL, CH, ZZ, ZW, GG, WG and LZ performed the experienment. HL, ZZ, YF, ZW, XT, KZ, YH and JX wrote the manuscript. All authors read and approved the final manuscript.

\section{Funding}

This work was supported by the National Natural Science Foundation of China (31471286 \& 81772693), National Major Scientific and Technological Special Project for Significant New Drugs Development (2019ZX09301-147), 1.3.5 project for disciplines of excellence of the West China Hospital, Sichuan University (ZYJC18007) and the Major Subject of the Science and Technology Department of Sichuan Province (2017SZ0015, 2019YFS0330 \& 2019YFS0108) 
Availability of data and materials

The dataset analyzed during this study are available in Oncomine, [www.oncomine.org] and TCGA, [http://cancergenome.nih.gov].

\section{Ethics approval and consent to participate}

The study was approved by the West China Hospital of Sichuan University Biomedical Ethics Committee (Ethical approval document: 2018-061). Blood samples from healthy donors were handled with necessary safety procedures and ethical requirements.

\section{Consent for publication}

Not applicable.

\section{Competing interests}

Z.Z, H.Y. and A.T. have filed patents related to this work. The other authors declare no competing interests.

\section{References}

1. Siegel RL, Miller KD, Jemal A. Cancer statistics, 2019. CA Cancer J Clin. 2019;69(1):7-34.

2. Qin A, Coffey DG, Warren EH, Ramnath N. Mechanisms of immune evasion and current status of checkpoint inhibitors in non-small cell lung cancer. Cancer Med. 2016;5(9):2567-78.

3. Zappa C, Mousa SA. Non-small cell lung cancer: current treatment and future advances. Transl Lung Cancer Res. 2016;5(3):288-300.

4. Torre LA, Bray F, Siegel RL, Ferlay J, Lortet-Tieulent J, Jemal A. Global cancer statistics, 2012. CA Cancer J Clin. 2015;65(2):87-108.

5. Bowman KJ, Al-Moneef MM, Sherwood BT, Colquhoun AJ, Goddard JC, Griffiths TRL, et al. Comet assay measures of DNA damage are predictive of bladder cancer cell treatment sensitivity in vitro and outcome in vivo. Int J Cancer. 2014;134(5):1102-11.

6. Wei X, Lai Y, Li J, Qin L, Xu Y, Zhao R, et al. PSCA and MUC1 in non-small-cell lung cancer as targets of chimeric antigen receptor T cells. Oncoimmunology. 2017;6(3):e1284722-e.

7. Chapoval Al, Ni J, Lau JS, Wilcox RA, Flies DB, Liu D, et al. B7-H3: a costimulatory molecule for T cell activation and IFN-gamma production. Nat Immunol. 2001;2(3):269-74.

8. Seaman S, Zhu Z, Saha S, Zhang XM, Yang MY, Hilton MB, et al. Eradication of Tumors through Simultaneous Ablation of CD276/B7-H3-Positive Tumor Cells and Tumor Vasculature. Cancer Cell. 2017;31(4):501 - 15.e8.

9. Hofmeyer KA, Ray A, Zang X. The contrasting role of B7-H3. Proc Natl Acad Sci U S A. 2008;105(30):10277-8. 
10. Inamura K, Yokouchi Y, Kobayashi M, Sakakibara R, Ninomiya H, Subat S, et al. Tumor B7-H3 (CD276) expression and smoking history in relation to lung adenocarcinoma prognosis. Lung Cancer. 2017;103:44-51.

11. Picarda E, Ohaegbulam KC, Zang X. Molecular Pathways: Targeting B7-H3 (CD276) for Human Cancer Immunotherapy. Clin Cancer Res. 2016;22(14):3425-31.

12. Li Y, Guo G, Song J, Cai Z, Yang J, Chen Z, et al. B7-H3 Promotes the Migration and Invasion of Human Bladder Cancer Cells via the PI3K/Akt/STAT3 Signaling Pathway. J Cancer. 2017;8(5):81624.

13. Du H, Hirabayashi K, Ahn S, Kren NP, Montgomery SA, Wang X, et al. Antitumor Responses in the Absence of Toxicity in Solid Tumors by Targeting B7-H3 via Chimeric Antigen Receptor T Cells. Cancer Cell. 2019;35(2):221 - 37.e8.

14. Tang $X$, Zhao S, Zhang Y, Wang Y, Zhang Z, Yang M, et al. B7-H3 as a Novel CAR-T Therapeutic Target for Glioblastoma. Mol Ther Oncolytics. 2019;14:279-87.

15. Majzner RG, Theruvath JL, Nellan A, Heitzeneder S, Cui Y, Mount CW, et al. CAR T Cells Targeting B7H3, a Pan-Cancer Antigen, Demonstrate Potent Preclinical Activity Against Pediatric Solid Tumors and Brain Tumors. Clin Cancer Res. 2019;25(8):2560-74.

16. Nehama D, Di lanni N, Musio S, Du H, Patané M, Pollo B, et al. B7-H3-redirected chimeric antigen receptor T cells target glioblastoma and neurospheres. EBioMedicine. 2019;47:33-43.

17. Huang B, Luo L, Wang J, He B, Feng R, Xian N, et al. B7-H3 specific T cells with chimeric antigen receptor and decoy PD-1 receptors eradicate established solid human tumors in mouse models. Oncoimmunology. 2019;9(1):1684127-.

18. Yu T-T, Zhang T, Lu X, Wang R-Z. B7-H3 promotes metastasis, proliferation, and epithelialmesenchymal transition in lung adenocarcinoma. Onco Targets Ther. 2018;11:4693-700.

19. Castellanos JR, Purvis IJ, Labak CM, Guda MR, Tsung AJ, Velpula KK, et al. B7-H3 role in the immune landscape of cancer. Am J Clin Exp Immunol. 2017;6(4):66-75.

20. Wu Z, Cheung NV. T cell engaging bispecific antibody (T-BsAb): From technology to therapeutics. Pharmacol Ther. 2018;182:161-75.

21. Perez P, Hoffman RW, Shaw S, Bluestone JA, Segal DM. Specific targeting of cytotoxic T cells by antiT3 linked to anti-target cell antibody. Nature. 1985;316(6026):354-6.

22. Bargou R, Leo E, Zugmaier G, Klinger M, Goebeler M, Knop S, et al. Tumor regression in cancer patients by very low doses of a T cell-engaging antibody. Science. 2008;321(5891):974-7.

23. Lopez-Albaitero A, Xu H, Guo H, Wang L, Wu Z, Tran H, et al. Overcoming resistance to HER2-targeted therapy with a novel HER2/CD3 bispecific antibody. Oncoimmunology. 2017;6(3):e1267891-e.

24. Ishiguro T, Sano Y, Komatsu S-I, Kamata-Sakurai M, Kaneko A, Kinoshita Y, et al. An anti-glypican 3/CD3 bispecific T cell-redirecting antibody for treatment of solid tumors. Sci Transl Med. 2017;9(410):eaal4291. 
25. Robinson HR, Qi J, Cook EM, Nichols C, Dadashian EL, Underbayev C, et al. A CD19/CD3 bispecific antibody for effective immunotherapy of chronic lymphocytic leukemia in the ibrutinib era. Blood. 2018;132(5):521-32.

26. Leong SR, Sukumaran S, Hristopoulos M, Totpal K, Stainton S, Lu E, et al. An anti-CD3/anti-CLL-1 bispecific antibody for the treatment of acute myeloid leukemia. Blood. 2017;129(5):609-18.

27. Li J, Piskol R, Ybarra R, Chen Y-JJ, Li J, Slaga D, et al. CD3 bispecific antibody-induced cytokine release is dispensable for cytotoxic T cell activity. Sci Transl Med. 2019;11(508):eaax8861.

28. Bispecific A. Antibody for MUC16 and CD3 Has Preclinical Antitumor Activity. Cancer Discov. 2019;9(8):994-.

29. Zhang $X$, Yang Y, Fan D, Xiong D. The development of bispecific antibodies and their applications in tumor immune escape. Experimental hematology oncology. 2017;6:12.

30. Caunt CJ, Sale MJ, Smith PD, Cook SJ. MEK1 and MEK2 inhibitors and cancer therapy: the long and winding road. Nat Rev Cancer. 2015;15(10):577-92.

31. Lugowska I, Koseła-Paterczyk H, Kozak K, Rutkowski P. Trametinib: a MEK inhibitor for management of metastatic melanoma. Onco Targets Ther. 2015;8:2251-9.

32. Kidger AM, Sipthorp J, Cook SJ. ERK1/2 inhibitors: New weapons to inhibit the RAS-regulated RAFMEK1/2-ERK1/2 pathway. Pharmacol Ther. 2018;187:45-60.

33. Yuan J, Ng WH, Tian Z, Yap J, Baccarini M, Chen Z, et al. Activating mutations in MEK1 enhance homodimerization and promote tumorigenesis. Sci Signal. 2018;11(554):eaar6795.

34. Lian T, Li C, Wang H. Trametinib in the treatment of multiple malignancies harboring MEK1 mutations. Cancer Treat Rev. 2019;81:101907-.

35. Thota R, Johnson DB, Sosman JA. Trametinib in the treatment of melanoma. Expert Opin Biol Ther. 2015;15(5):735-47.

36. Roskoski R. Jr. Properties of FDA-approved small molecule protein kinase inhibitors. Pharmacological research. 2019;144:19-50.

37. Li H, Hu Y, Huang J, Feng Y, Zhang Z, Zhong K, et al. Zika virus NS5 protein inhibits cell growth and invasion of glioma. Biochem Biophys Res Commun. 2019;516(2):515-20.

38. Győrffy B, Surowiak P, Budczies J, Lánczky A. Online survival analysis software to assess the prognostic value of biomarkers using transcriptomic data in non-small-cell lung cancer. PloS one. 2013;8(12):e82241.

39. Rhodes DR, Kalyana-Sundaram S, Mahavisno V, Varambally R, Yu J, Briggs BB, et al. Oncomine 3.0: genes, pathways, and networks in a collection of 18,000 cancer gene expression profiles. Neoplasia (New York NY). 2007;9(2):166-80.

40. Garber ME, Troyanskaya OG, Schluens K, Petersen S, Thaesler Z, Pacyna-Gengelbach M, et al. Diversity of gene expression in adenocarcinoma of the lung. Proc Natl Acad Sci U S A. 2001;98(24):13784-9. 
41. Du S, Guan Z, Hao L, Song Y, Wang L, Gong L, et al. Fructose-bisphosphate aldolase a is a potential metastasis-associated marker of lung squamous cell carcinoma and promotes lung cell tumorigenesis and migration. PloS one. 2014;9(1):e85804.

42. Okayama H, Kohno T, Ishii Y, Shimada Y, Shiraishi K, Iwakawa R, et al. Identification of genes upregulated in ALK-positive and EGFR/KRAS/ALK-negative lung adenocarcinomas. Cancer Res. 2012;72(1):100-11.

43. Selamat SA, Chung BS, Girard L, Zhang W, Zhang Y, Campan M, et al. Genome-scale analysis of DNA methylation in lung adenocarcinoma and integration with mRNA expression. Genome research. 2012;22(7):1197-211.

44. Blaveri E, Simko JP, Korkola JE, Brewer JL, Baehner F, Mehta K, et al. Bladder cancer outcome and subtype classification by gene expression. Clin Cancer Res. 2005;11(11):4044-55.

45. Lee JS, Leem SH, Lee SY, Kim SC, Park ES, Kim SB, et al. Expression signature of E2F1 and its associated genes predict superficial to invasive progression of bladder tumors. Journal of clinical oncology: official journal of the American Society of Clinical Oncology. 2010;28(16):2660-7.

46. Watanabe M, Sowa Y, Yogosawa M, Sakai T. Novel MEK inhibitor trametinib and other retinoblastoma gene (RB)-reactivating agents enhance efficacy of 5-fluorouracil on human colon cancer cells. Cancer Sci. 2013;104(6):687-93.

47. Martinez-Garcia M, Banerji U, Albanell J, Bahleda R, Dolly S, Kraeber-Bodéré F, et al. First-in-human, phase I dose-escalation study of the safety, pharmacokinetics, and pharmacodynamics of R05126766, a first-in-class dual MEK/RAF inhibitor in patients with solid tumors. Clin Cancer Res. 2012;18(17):4806-19.

48. Vella LJ, Pasam A, Dimopoulos N, Andrews M, Knights A, Puaux A-L, et al. MEK inhibition, alone or in combination with BRAF inhibition, affects multiple functions of isolated normal human lymphocytes and dendritic cells. Cancer Immunol Res. 2014;2(4):351-60.

49. Liu L, Mayes PA, Eastman S, Shi H, Yadavilli S, Zhang T, et al. The BRAF and MEK Inhibitors Dabrafenib and Trametinib: Effects on Immune Function and in Combination with Immunomodulatory Antibodies Targeting PD-1, PD-L1, and CTLA-4. Clin Cancer Res. 2015;21(7):1639-51.

50. Ebert PJR, Cheung J, Yang Y, McNamara E, Hong R, Moskalenko M, et al. MAP Kinase Inhibition Promotes T Cell and Anti-tumor Activity in Combination with PD-L1 Checkpoint Blockade. Immunity. 2016;44(3):609-21.

51. Bommareddy PK, Aspromonte S, Zloza A, Rabkin SD, Kaufman HL. MEK inhibition enhances oncolytic virus immunotherapy through increased tumor cell killing and T cell activation. Sci Transl Med. 2018;10(471):eaau0417.

52. Kang S-H, Keam B, Ahn Y-O, Park H-R, Kim M, Kim TM, et al. Inhibition of MEK with trametinib enhances the efficacy of anti-PD-L1 inhibitor by regulating anti-tumor immunity in head and neck squamous cell carcinoma. Oncoimmunology. 2018;8(1):e1515057-e. 
53. Atefi M, Avramis E, Lassen A, Wong DJL, Robert L, Foulad D, et al. Effects of MAPK and PI3K pathways on PD-L1 expression in melanoma. Clin Cancer Res. 2014;20(13):3446-57.

54. Frederick DT, Piris A, Cogdill AP, Cooper ZA, Lezcano C, Ferrone CR, et al. BRAF inhibition is associated with enhanced melanoma antigen expression and a more favorable tumor microenvironment in patients with metastatic melanoma. Clin Cancer Res. 2013;19(5):1225-31.

55. Kang F-B, Wang L, Jia H-C, Li D, Li H-J, Zhang Y-G, et al. B7-H3 promotes aggression and invasion of hepatocellular carcinoma by targeting epithelial-to-mesenchymal transition via JAK2/STAT3/Slug signaling pathway. Cancer Cell Int. 2015;15:45-.

56. Wang J, Chong KK, Nakamura Y, Nguyen L, Huang SK, Kuo C, et al. B7-H3 associated with tumor progression and epigenetic regulatory activity in cutaneous melanoma. J Invest Dermatol. 2013;133(8):2050-8.

57. Powderly J, Cote G, Flaherty K, Szmulewitz RZ, Ribas A, Weber J, et al. Interim results of an ongoing Phase I, dose escalation study of MGA271 (Fc-optimized humanized anti-B7-H3 monoclonal antibody) in patients with refractory B7-H3-expressing neoplasms or neoplasms whose vasculature expresses B7-H3. Journal for ImmunoTherapy of Cancer. 2015;3(Suppl 2):08.

58. Souweidane MM, Kramer K, Pandit-Taskar N, Zhou Z, Haque S, Zanzonico P, et al. Convectionenhanced delivery for diffuse intrinsic pontine glioma: a single-centre, dose-escalation, phase 1 trial. The Lancet Oncology. 2018;19(8):1040-50.

\section{Additional Files}

Additional file 1: Figure S1. Expression of B7-H3 in NSCLC and BC derived from Oncomine database. The ten studies showed the differential expression of B7-H3 in NSCLS and BC tissues compared with normal tissues. 1-6 in (a) and 1-4 in (b) represented NSCLC and BC, respectively. Darker red indicated higher B7H3 expression in the chips.

Additional file 2: Figure S2. B7-H3 expression on tumor cells in NSCLC and BC mice models. Immunofluorescence staining of B7-H3 in H460 (a) and T24 (b) tumor frozen tissue sections. Scale bar, $50 \mu \mathrm{m}$.

Additional file 3: Figure S3. Morphology of tumor cells after co-culture with human T cells. A549 (a), H460 (b) or T24 (c) cells were co-cultured with T cells for 12 or 24 hours at a ratio of E:T=1:1 or 1:4. The BiAb group was treated with B7-H3×CD3 BiAb at a concentration of $5 \mu \mathrm{g} / \mathrm{mL}$. Scale bar, $50 \mu \mathrm{m}$.

Additional file 4: Figure S4. The ratio of CD4 and CD8 positive T cells in coculture assay with tumor cells. Dot plot diagram of flow cytometry showing CD4+ and CD8+ percentage of human T cells after coculture with $\mathrm{H} 460$ (a) or T24 (b) cells for $24 \mathrm{~h}$ in the presence of $1 \mu \mathrm{M}$ trametinib alone or in combination with 5 $\mu \mathrm{g} / \mathrm{mL}$ B7-H3×CD3 BiAb.

Additional file 5: Figure S5. H\&E stained images of liver, spleen, kidney, heart and lung in H460 mice models. 
Figures

a

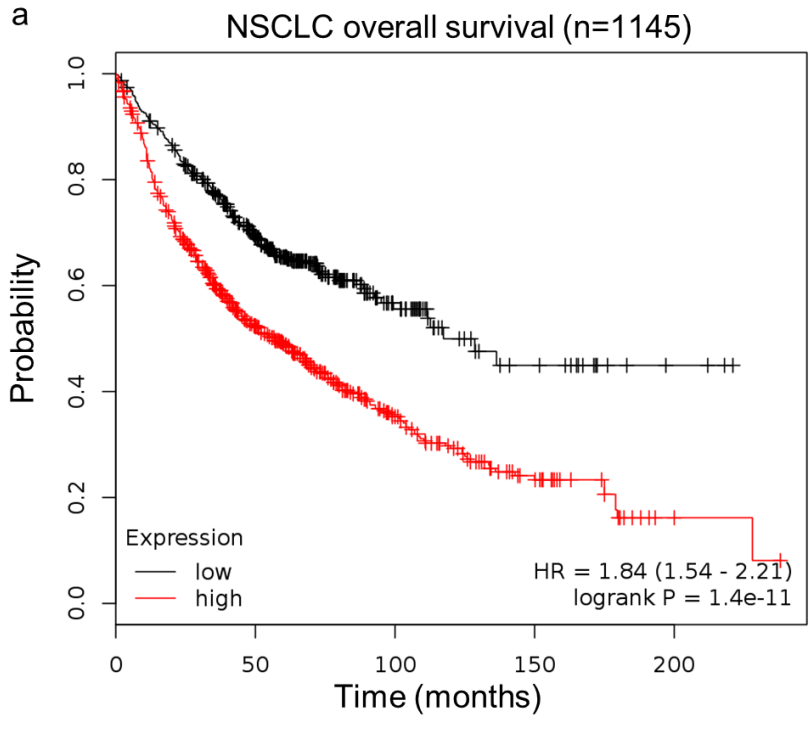

c

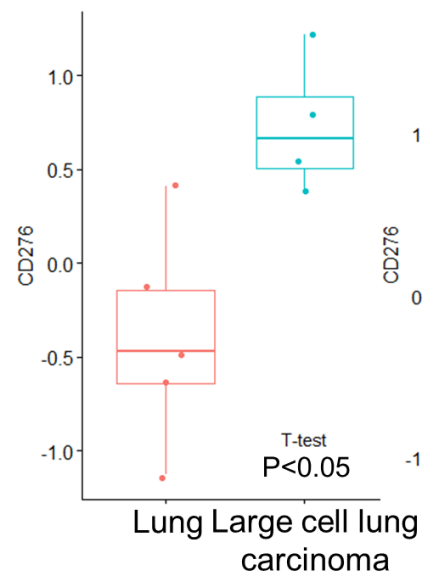

e

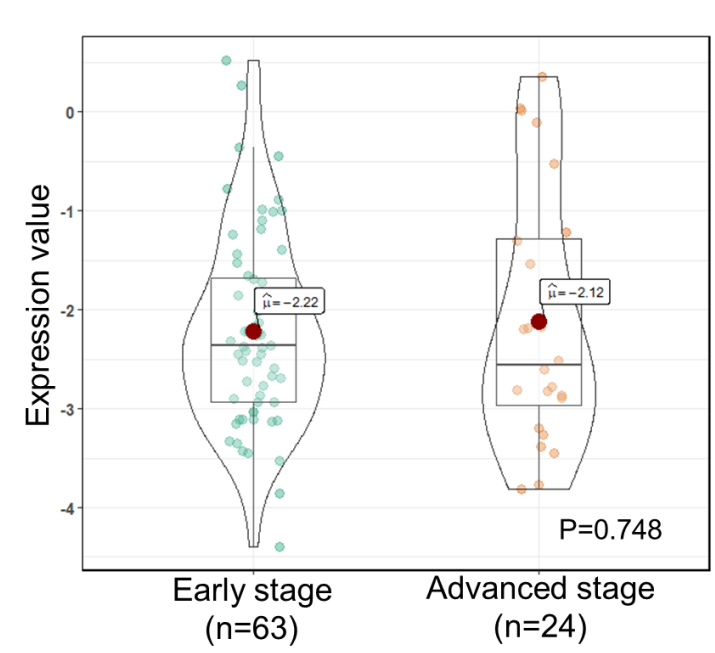

b

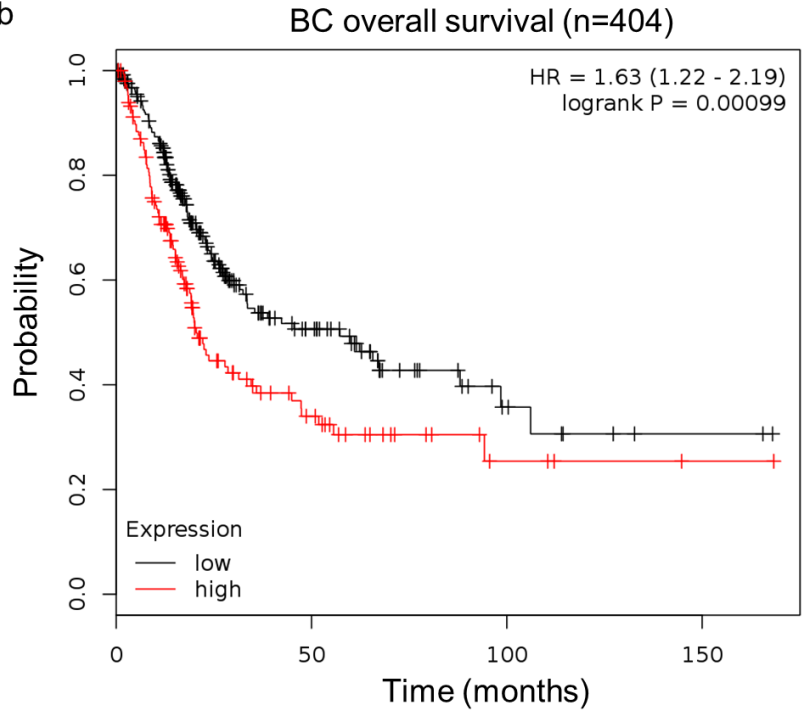

d

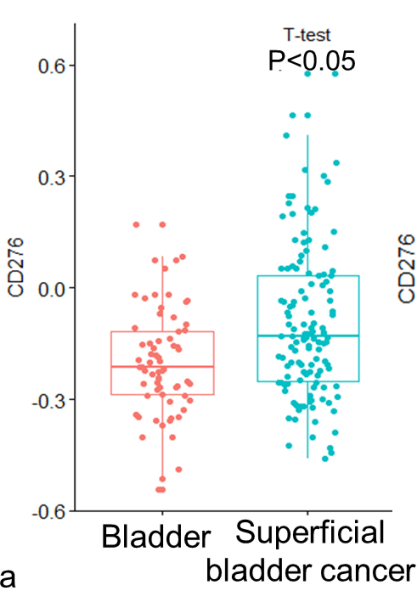

$f$

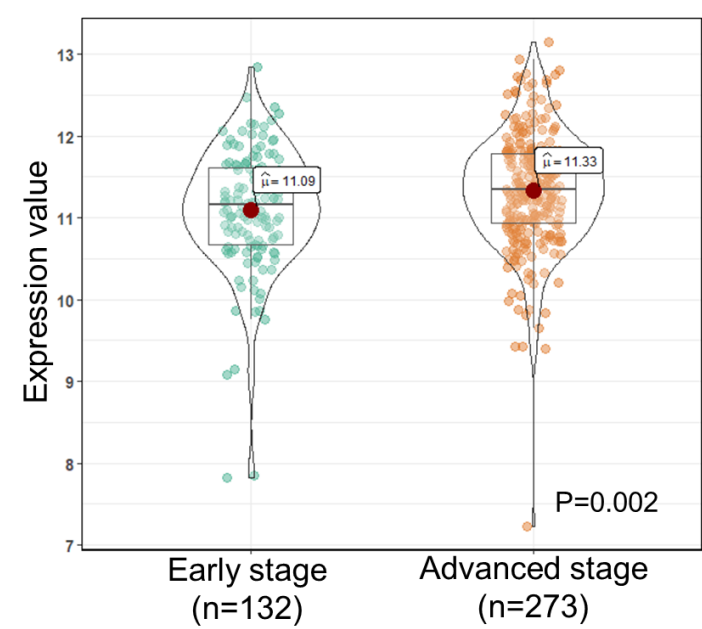

\section{Figure 1}

Analysis of B7-H3 expression and survival in NSCLC and BC. (a and b) Overall survival curves based on B7-H3 expression in NSCLC and BC patients (KM Plotter database). (c and d) Box plots derived from expression data comparing expression of B7-H3 in normal and cancer subtypes (Oncomine database). 
The analysis was shown in NSCLC subtypes relative to normal lung (c) and in BC subtypes relative to normal bladder (d). (e and f) Comparison of B7-H3 expression among NSCLC (e) (Oncomine database) and BC (f) (TCGA database) patients at different clinical stages.
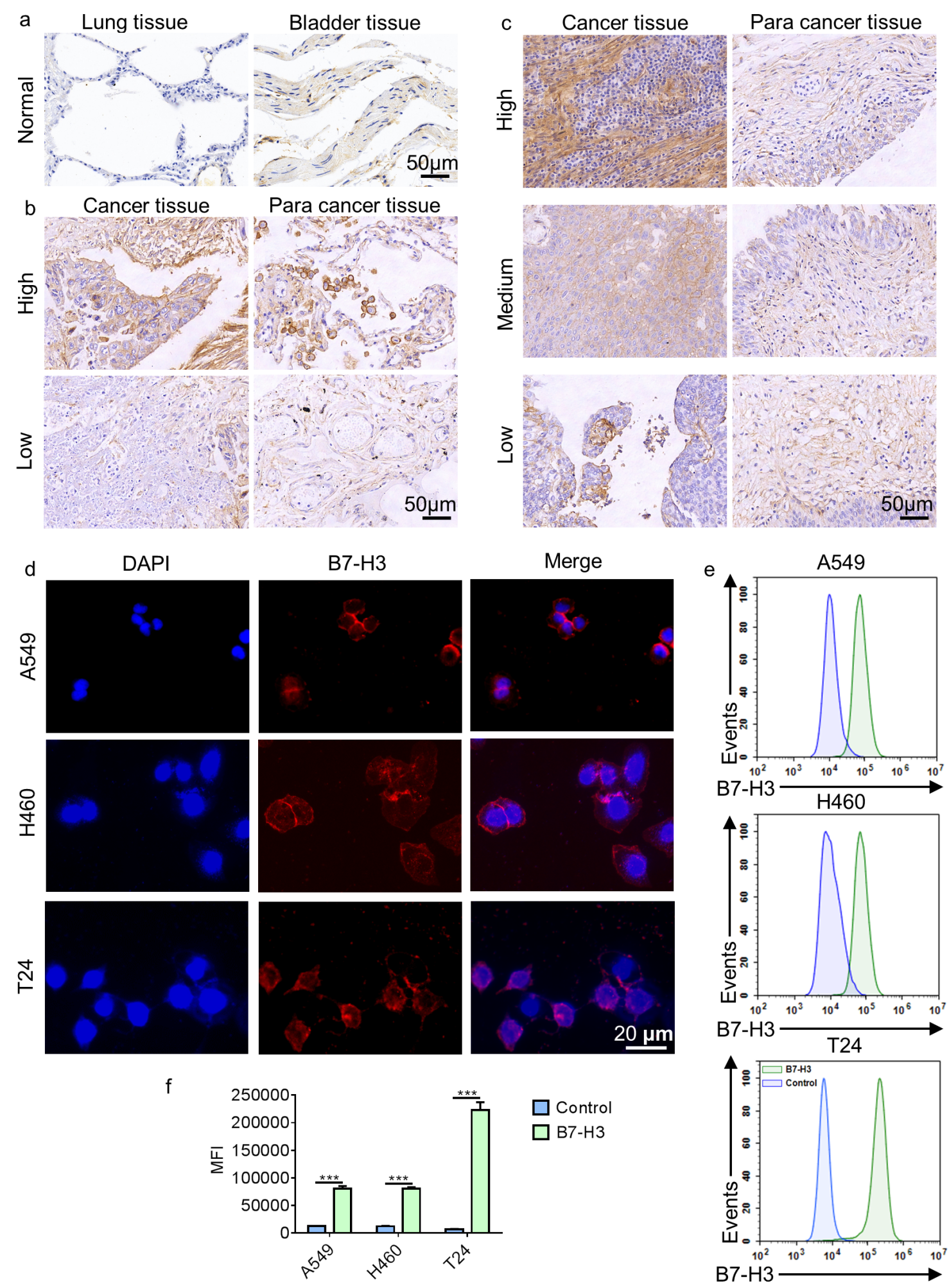

Figure 2

Expression of $\mathrm{B} 7-\mathrm{H} 3$ on human NSCLC and $\mathrm{BC} .(\mathrm{a}, \mathrm{b}$ and $\mathrm{c}$ ) $\mathrm{B} 7-\mathrm{H} 3 \mathrm{IHC}$ staining patterns. Representative cases of normal lung and bladder samples (a), NSCLC (b) and BC (c) samples including para cancer 


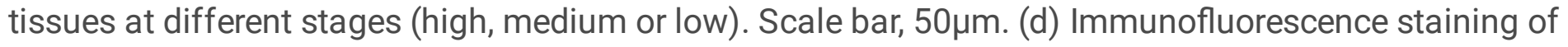
A549, H460, T24 tumor cells for B7-H3. Scale bar, $20 \mu \mathrm{m}$. (e) Quantification of B7-H3 expression level in A549, H460 and T24 cell lines by flow cytometry. Histograms represent the measured fluorescence of cells incubated with the B7-H3 antibody. (f) Histogram of the mean fluorescence intensity. ${ }^{* \star *} \mathrm{P}<0.001$.

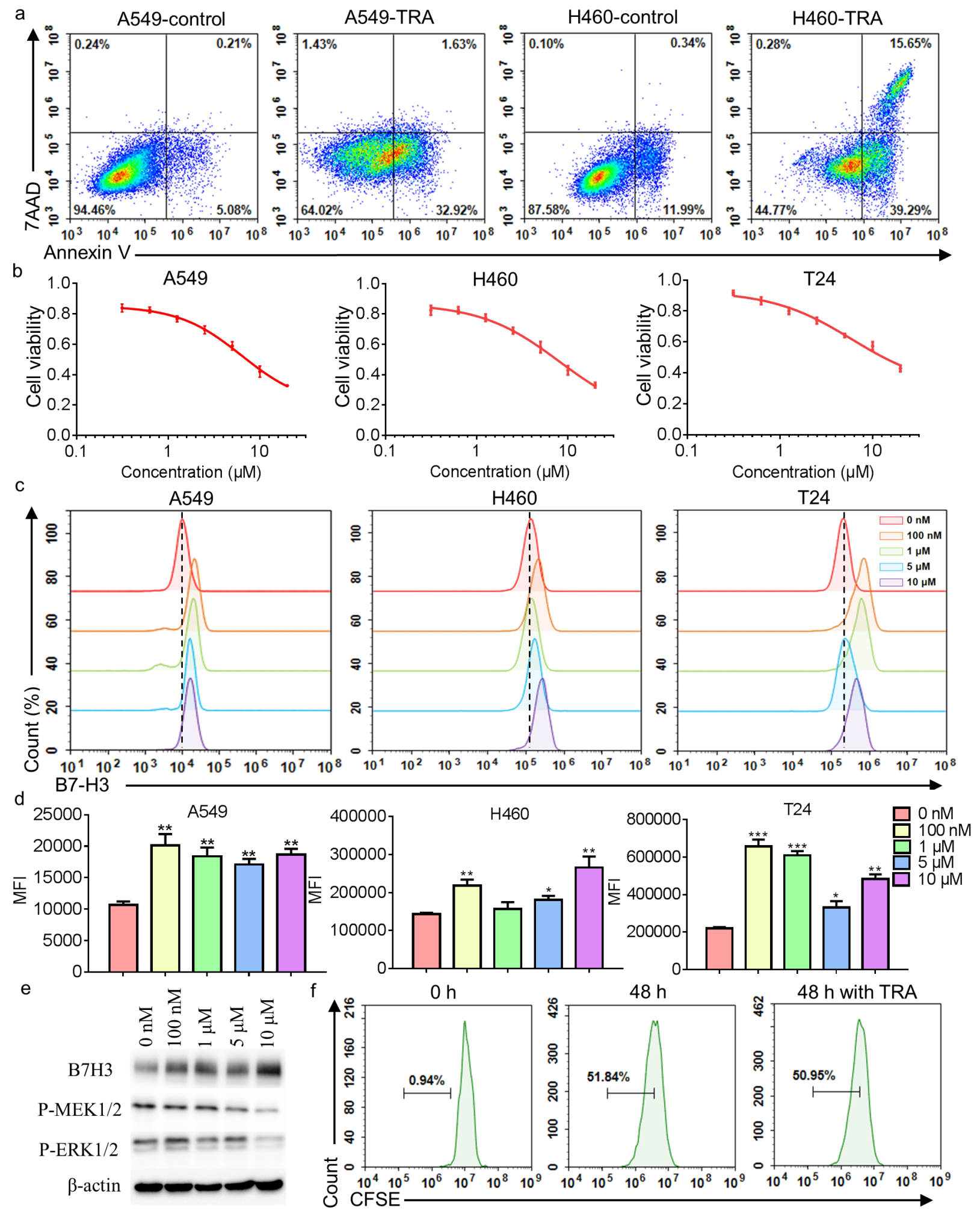

Figure 3 
Effects of MEK inhibitor trametinib in A549, H460, T24 and human T cells. (a) Apoptosis detection with annexin V-FITC/7AAD double staining by flow cytometry. A549 and H460 cells were cultured with $10 \mu \mathrm{M}$ trametinib for 48 hours. (b) Cell viability of A549, H460 and T24 cells after exposure to trametinib with various concentrations. After 48 hours of treatment, cell viability was measured using Cell Counting Kit-8 assays. (c) B7-H3 expression after trametinib treatment with indicated concentrations by flow cytometry. Histograms represent the measured fluorescence of cells incubated with the B7-H3 antibody. (d) Histogram of the mean fluorescence intensity. ${ }^{*} P<0.05$, ${ }^{\star *} P<0.01$, ${ }^{\star \star *} P<0.001$ difference between the control and trametinib administration groups. (e) Western blot analysis of B7-H3, P-MEK and P-ERK expression in A549 cells after trametinib treatment with indicated concentrations. Expression of $\beta$-actin was used as an internal control. (f) Proliferation (CFSE dilution assay) of human T cells after 48 hours of treatment with $1 \mu \mathrm{M}$ trametinib by flow cytometry. Histograms represent the measured fluorescence of cells incubated with CFSE. 

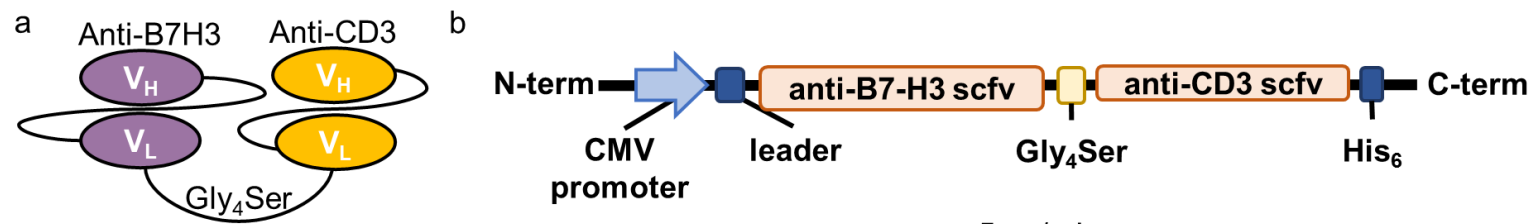

c

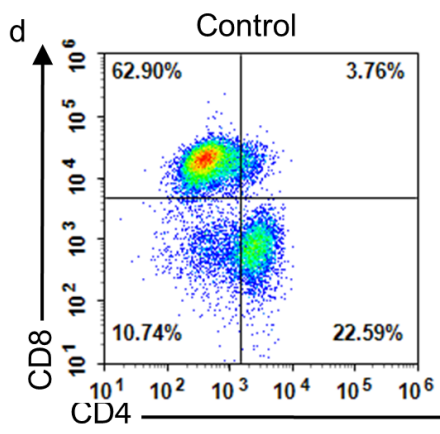
promoter
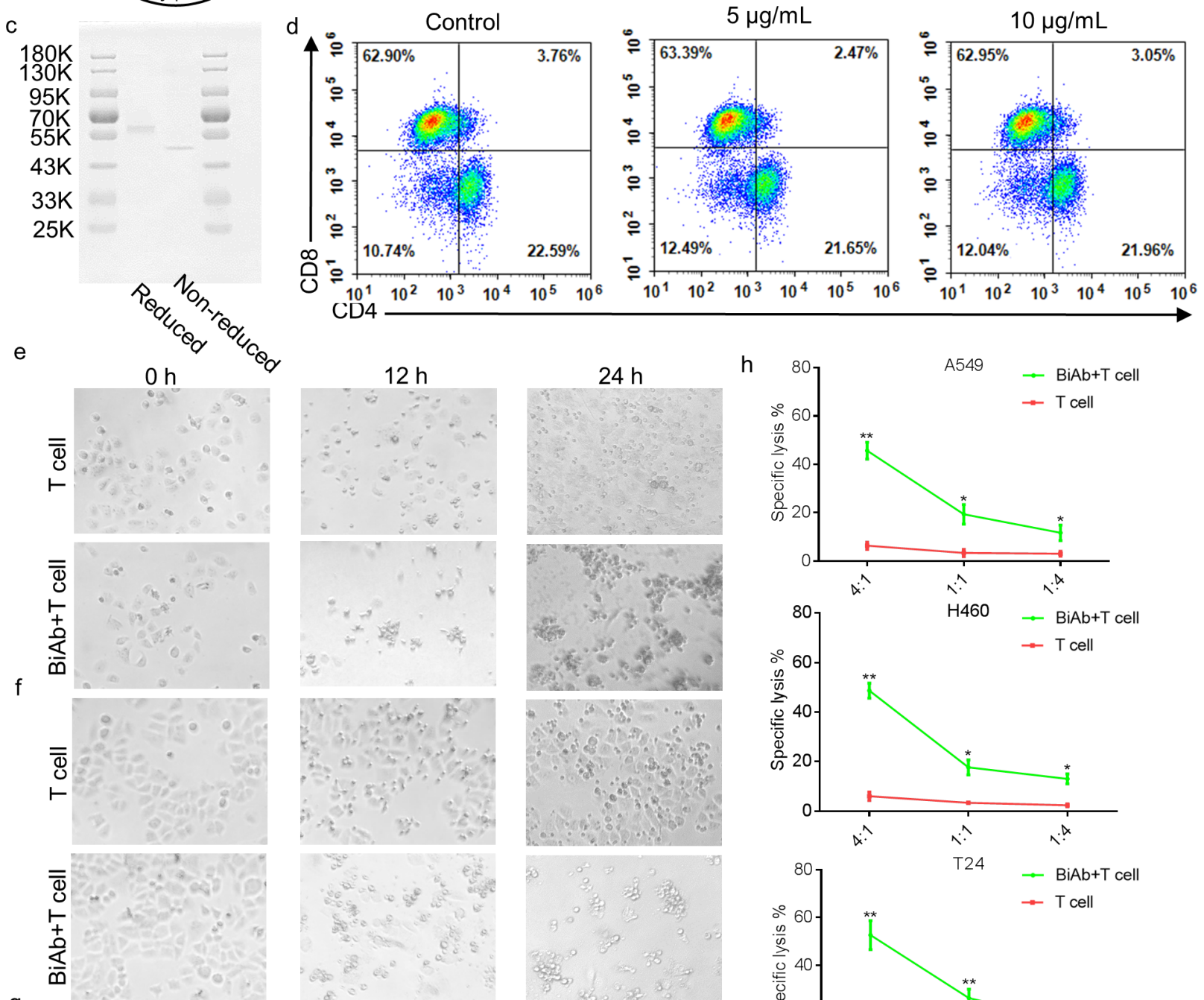

g
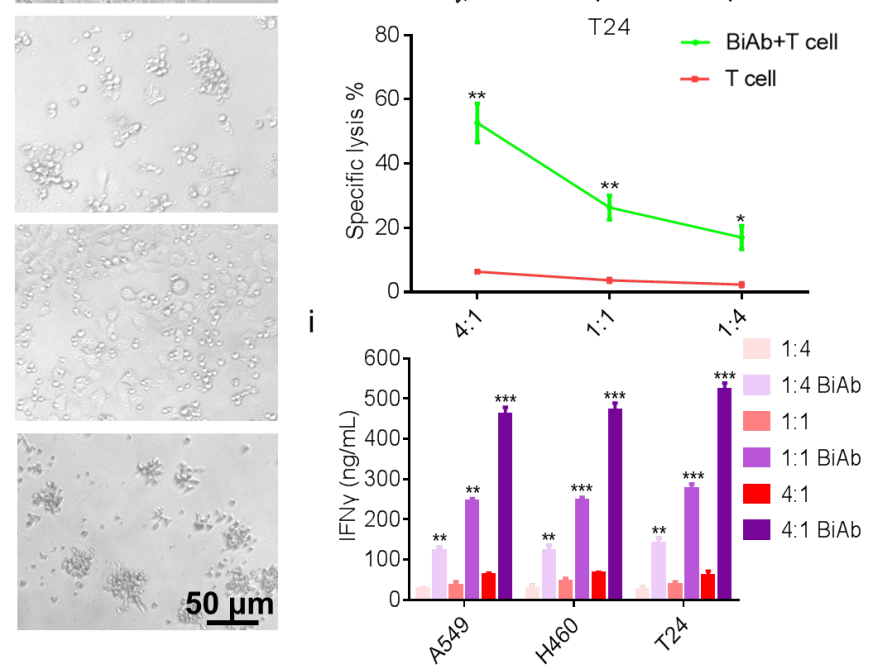

Figure 4

Construction, characterization and cytotoxicity of $\mathrm{B} 7-\mathrm{H} 3 \times \mathrm{CD} 3 \mathrm{BiAb}$. (a) The schematic representation of B7-H3 $\times$ CD3 BiAb. (b) Schematic diagram of B7-H3 $\times$ CD3 BiAb expression vector. (c) SDS-PAGE analysis of B7-H3×CD3 BiAb. The antibody was run on reducing and non-reducing SDS-PAGE gels. (d) Dot plot diagram of flow cytometry showing CD4+ and CD8+ percentage of human T cells after 5 or $10 \mu \mathrm{g} / \mathrm{mL}$ B7$\mathrm{H} 3 \times \mathrm{CD} 3 \mathrm{BiAb}$ treatment for 48 hours. (e, $\mathrm{f}$ and $\mathrm{g}$ ) Morphology of tumor cells after co-culture with human 
T cells. A549 (e), H460 (f) or T24 (g) cell lines were co-cultured with T cells for 12 or 24 hours at a ratio of $\mathrm{E}: \mathrm{T}=4: 1$. Group "BiAb+T cell" was treated with $\mathrm{B} 7-\mathrm{H} 3 \times \mathrm{CD} 3 \mathrm{BiAb}$ at a concentration of $5 \mu \mathrm{g} / \mathrm{mL}$. Scale bar, $50 \mu \mathrm{m}$. (h) $51 \mathrm{Cr}$-release assays of T cells against A549, H460 and T24 cell lines with $5 \mu \mathrm{g} / \mathrm{mL}$ B7$\mathrm{H} 3 \times \mathrm{CD} 3 \mathrm{BiAb}$ in different E:T ratios. ${ }^{*} \mathrm{P}<0.05,{ }^{*} \mathrm{P}<0.01$. (i) Quantification of IFN- $\gamma$ by ELISA in the supernatant 24 hours after coculture of T cells with A549, H460 or T24 cell lines at different E:T ratio. Group "BiAb" was treated with B7-H3×CD3 BiAb at a concentration of $5 \mu \mathrm{g} / \mathrm{mL} .{ }^{* * P}<0.01$, ${ }^{* * *} \mathrm{P}<0.001$.
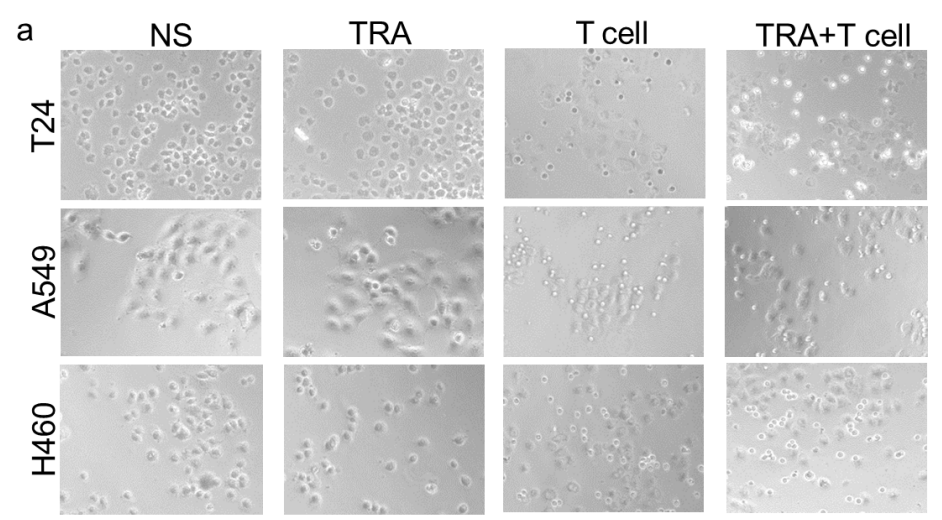

$\mathrm{Bi} A b+\mathrm{T}$ cell $\mathrm{TRA}+\mathrm{BiA} b+\mathrm{T}$ cell
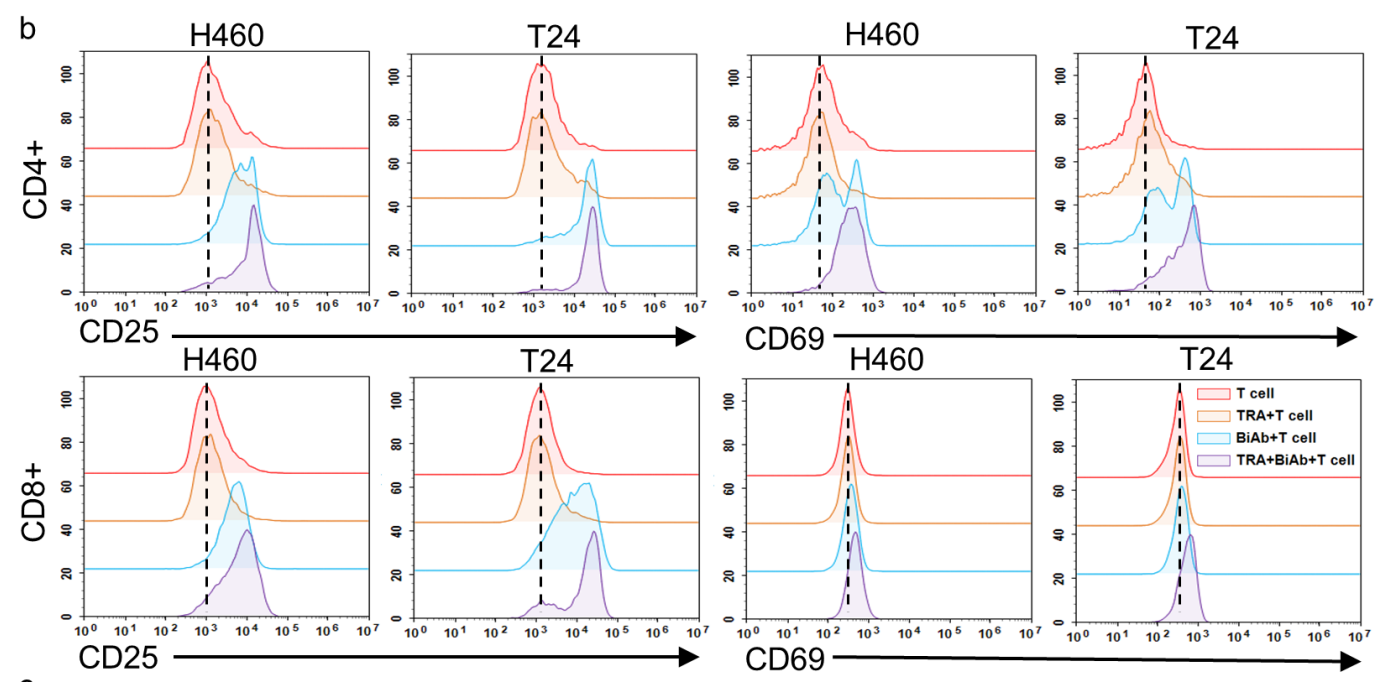

C
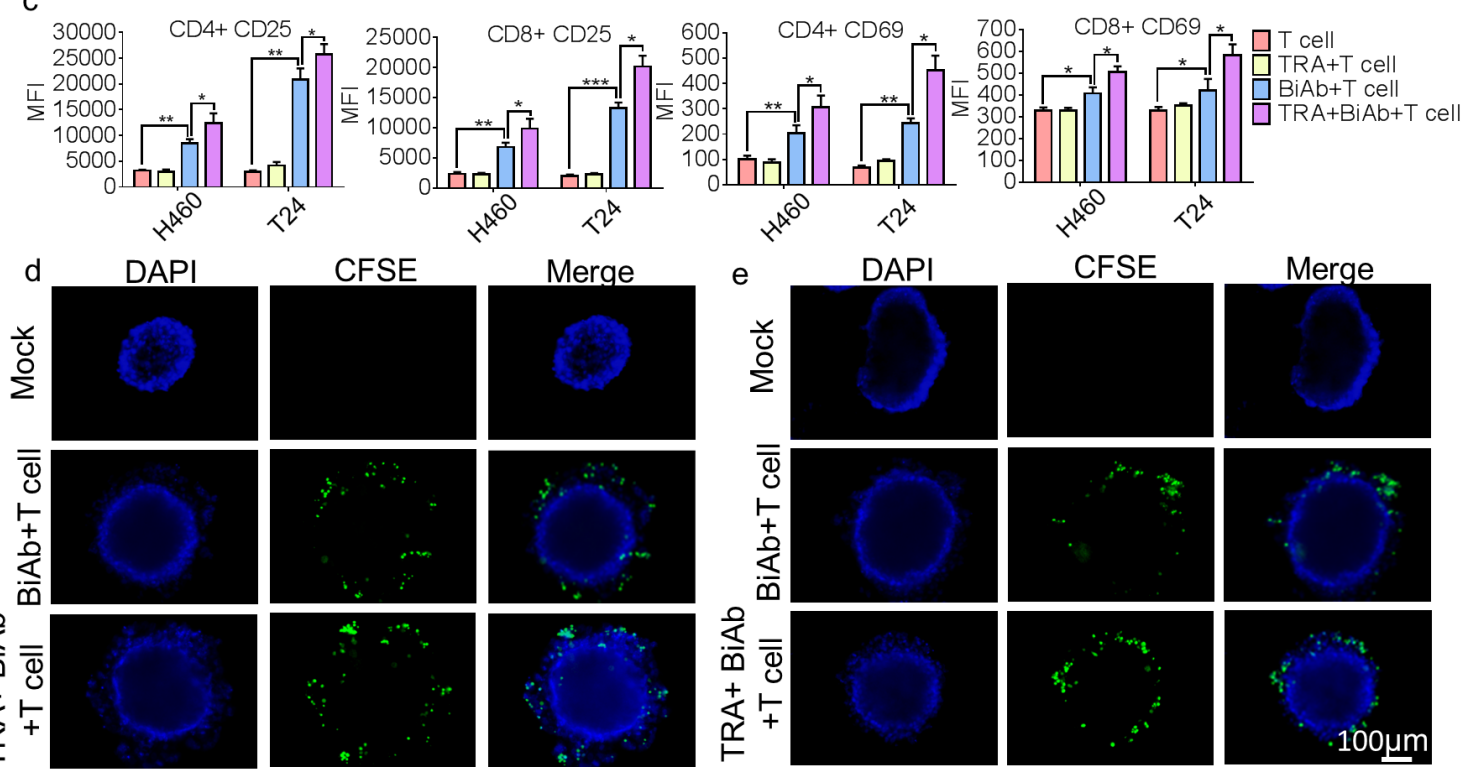

Figure 5 
Antitumor activity by $\mathrm{B} 7-\mathrm{H} 3 \times \mathrm{CD} 3 \mathrm{BiAb}$ in combination with trametinib in vitro. (a) Morphology of tumor cells after various treatments for 12 hours. Scare bar, $50 \mu \mathrm{m}$. (b) Activation signal of human $\mathrm{T}$ cells after coculture with tumor cells by adding $1 \mu \mathrm{M}$ trametinib alone or in combination with $5 \mu \mathrm{g} / \mathrm{mL}$ B7-H3×CD3 BiAb. Cells were collected 24 hours after coculture with $\mathrm{H} 460$ and T24 cell lines and stained with antibodies against CD4, CD8, CD25, CD69 for flow cytometry. (c) Histogram of the mean fluorescence intensity. ${ }^{*} \mathrm{P}<0.05,{ }^{*} \mathrm{P}<0.01$, ${ }^{* *} \mathrm{P}<0.001$. ( $\mathrm{d}$ and e) Killing activity of $\mathrm{B} 7-\mathrm{H} 3 \times \mathrm{CD} 3 \mathrm{BiAb}$ or in combination with trametinib was detected using the 3D tumorsphere model. A549 (d) and H460 (e) tumorspheres were cocultured with CFSE labeled T cells including $5 \mu \mathrm{g} / \mathrm{mL}$ B7-H3×CD3 BiAb alone or in combination with $1 \mu \mathrm{M}$ trametinib for 12 hours. Scare bar, $100 \mu \mathrm{m}$. 
a

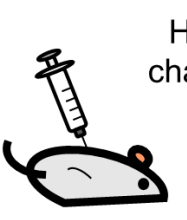

H460 or T24

challenge (s.c.)
T cells or in combination with

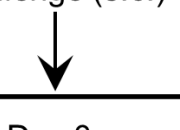

Day 0

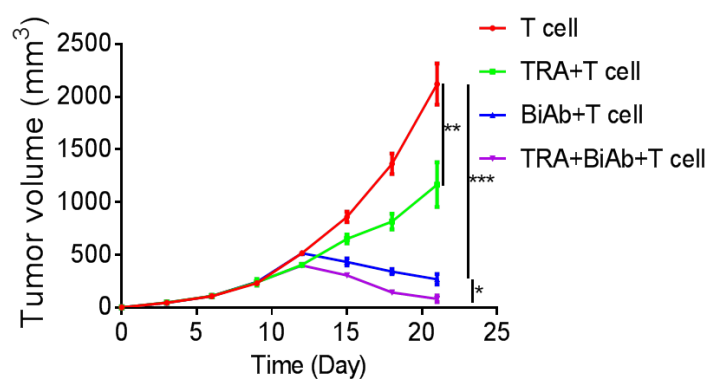

d

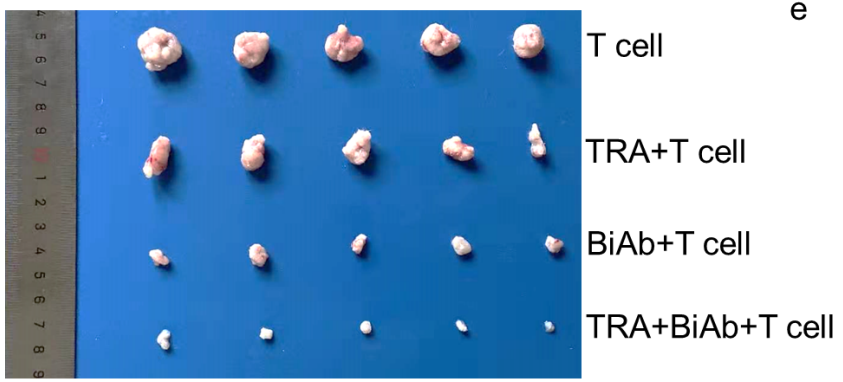

f

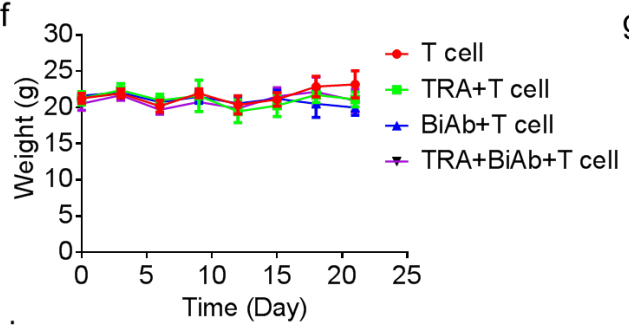

i

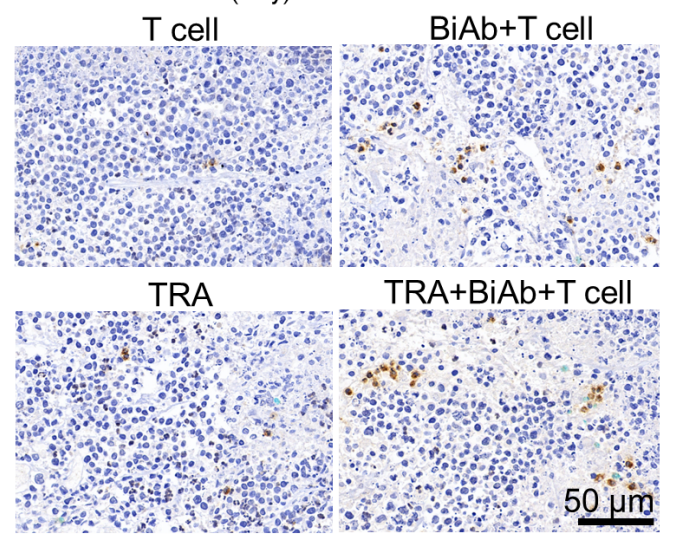

Day 20 Day 21

$9 \quad 3010 \rightarrow T$ cell

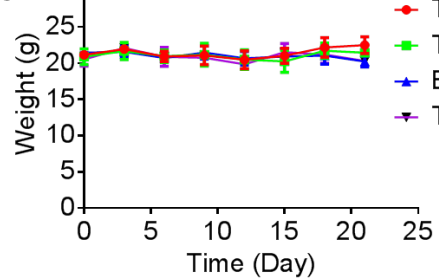

- TRA+T cell

+ BiAb+T cell

$\rightarrow$ TRA+BiAb+T cell
Trametinib (p.o.)
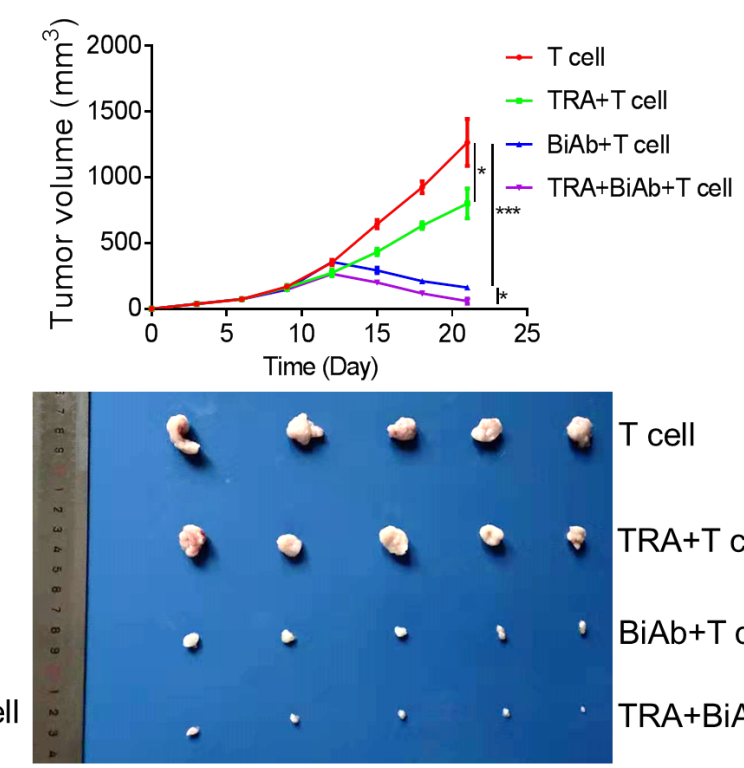

T cell

$T R A+T$ cell

$B i A b+T$ cell

$T R A+B i A b+T$ cell
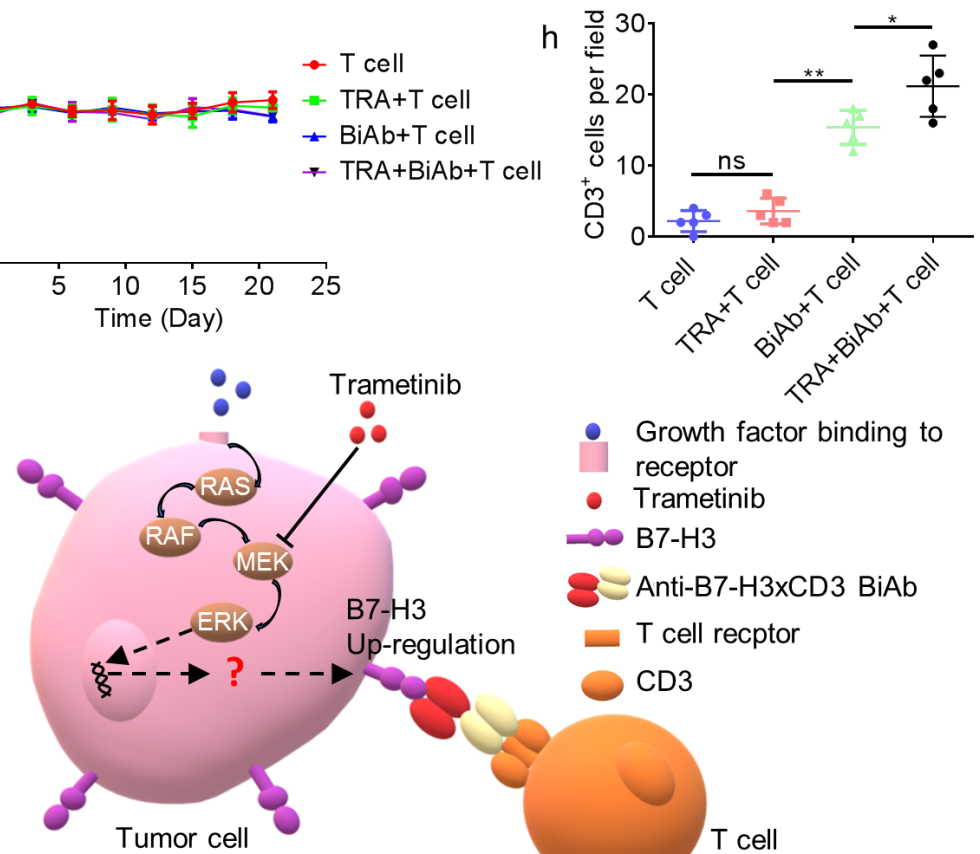

- Growth factor binding to

receptor

- Trametinib

$-\infty$ B7-H3

8 Anti-B7-H3xCD3 BiAb

- T cell recptor

CD3

\section{Figure 6}

Antitumor activity by $\mathrm{B} 7-\mathrm{H} 3 \times \mathrm{CD} 3 \mathrm{BiAb}$ in combination with trametinib in vivo. (a) Experiment design scheme. (b and c) Tumor growth curves from H460 (b) and T24 (c) mice models treated with T cell, T cell with trametinib, the BiAb or the BiAb combined with trametinib. Tumor volume measurements were recorded every 3 days. (d and e) Tumors from H460 (d) and T24 (e) mice models on day 21 are shown. (f and g) Bodyweight of H460 (f) and T24 (g) mice treated with T cell, T cell with trametinib, the BiAb or the 
BiAb combined with trametinib. Bodyweight measurements were recorded every 3 days. $(h)$ Representative images of tumor-infiltrating T cells in $\mathrm{H} 460$ mice models. After different treatment methods, T cells were detected by immunohistochemical staining for CD3. Scare bar, 50 $\mu \mathrm{m}$. (i) Quantification of T-cell infiltration from $\mathrm{H} 460$ mice models. ${ }^{*} P<0.05,{ }^{*} \mathrm{P}<0.01$. (j) Schematic summary for synergistic effect between MEK inhibitor trametinib and B7-H3×CD3 BiAb in killing NSCLC and BC cells.

\section{Supplementary Files}

This is a list of supplementary files associated with this preprint. Click to download.

- Additionalfile1.TIF

- Additionalfile5.TIF

- Additionalfile3.TIF

- Additionalfile4.TIF

- Additionalfile2.TIF 